\title{
Importância da determinação do ponto de carga zero como característica de tingimento de fibras proteicas
}

\author{
Point of zero charge of protein fibers, \\ an important characteristic for dyeing
}

\author{
Fernando Giacomni ${ }^{1}$, Maira Amanda Benedet Menegazzo ${ }^{2}$, \\ Márcia Gomes da Silva ${ }^{3}$, Andreia Bortoluzzi da Silva ${ }^{3}$, \\ Maria Angélica Simões Dornellas de Barros ${ }^{2}$
}

\author{
${ }^{1}$ Laboratório de Beneficiamento Têxtil - Instituto Federal de Santa Catarina, Campus Araranguá - IFSC. CP: 88905-112, \\ Araranguá, SC \\ e-mail: fernando.giacomini@ifsc.edu.br \\ ${ }^{2}$ Programa de Pós-Graduação em Engenharia Química - Universidade Estadual de Maringá - PEQ/UEM. CP: 87020-900, \\ Maringá, PR \\ e-mail:mmenegazzo@outlook.com; angelica@deq.uem.br \\ ${ }^{3}$ Departamento de Engenharia Têxtil - Universidade Estadual de Maringá, Campus Regional de Goioerê - DET/UEM. \\ CP: 87360-000, Goioerê, PR \\ e-mail:mgsilva4@uem.br; abortoluzzi2@uem.br
}

\section{RESUMO}

O ponto de carga zero é uma característica eletrocinética relacionada aos materiais anfóteros, como as fibras proteicas, cuja determinação e conhecimento é crucial para os processos de tingimento e acabamento das mesmas. Esta característica influencia na adsorção do corante do tipo ácido, principal classe de corante aplicado no tingimento das fibras de seda e lã. Durante o tingimento a carga iônica das fibras proteicas é dependente do $\mathrm{pH}$ do banho em que se encontram. No $\mathrm{pH}$ correspondente ao ponto de carga zero $\left(\mathrm{pH} \mathrm{PCZ}_{\mathrm{P}}\right)$, a fibra proteica possui carga neutra. Quando em presença de um banho cujo $\mathrm{pH}$ é inferior ao $\mathrm{pH}_{\mathrm{PCZ}}$, a fibra fica carregada positivamente e pode, dessa forma, formar ligações iônicas com as moléculas de corante que estão carregados negativamente. Neste artigo, o pH correspondente ao ponto de carga zero foi determinado por um método denominando "experimento dos 11 pontos". Este método necessita de um aparato experimental mais simples e acessível do que os métodos utilizados na determinação do ponto isoelétrico, uma outra característica eletrocinética correlata dos materiais anfóteros. Para a fibra de seda e lã, foram encontrados $\mathrm{pH}_{\mathrm{PCZ}}$ iguais a 3,8 e 6,3 respectivamente. Tingimentos com corante ácido foram realizados com valores de $\mathrm{pH}$ acima e abaixo do $\mathrm{pH}_{\mathrm{PCZ}}$. As amostras tingidas em $\mathrm{pH}$ menor que o $\mathrm{pH}_{\mathrm{PCZ}}$, apresentaram maior intensidade colorística, evidenciando a formação de ligações iônicas entre corante e fibra. Já as amostras tingidas em pH maior que o $\mathrm{pH}_{\mathrm{PCZ}}$, pelo contrário, resultaram em menor intensidade colorística. Estes resultados comprovam a importância de se conhecer o ponto de carga zero das fibras proteicas e assim, determinar o melhor pH de tingimento das mesmas.

Palavras-chave: Ponto de carga zero. Seda. Lã. Tingimento.

\section{ABSTRACT}

The point of zero charge is an electrokinetic characteristic related to amphoteric materials such as protein fibers, whose determination and knowledge is crucial for the dyeing and finishing processes of the same. This characteristic influences the adsorption of acid type dye, main dye class applied in dyeing of silk and wool fibers. During the dyeing the ionic charge of the protein fibers is dependent of the $\mathrm{pH}$ of the bath in which they are. In the $\mathrm{pH}$ corresponding to the point of zero charge $\left(\mathrm{pH}_{\mathrm{PZC}}\right)$, protein fiber has a neutral charge. When in the presence of a bath whose $\mathrm{pH}$ is lower than $\mathrm{pH}_{\mathrm{PZC}}$, the fiber is positively charged and can thus form ionic bonds with the dye molecules that are negatively charged. In this article, the $\mathrm{pH}$ corresponding to the point of zero charge was determined by a calling method "experiment of 11 points". This method requires 
a simpler experimental apparatus and accessible than the methods used in determining the isoelectric point, another related electrokinetic characteristic of amphoteric materials. For silk fiber and wool were found $\mathrm{pH}_{\mathrm{PZC}}$ equal to 3.8 and 6.3 respectively. Dyeing with acid dye were carried out at $\mathrm{pH}$ values above and below the $\mathrm{pH}_{\mathrm{PZC}}$. The samples dyed at $\mathrm{pH}$ lower than $\mathrm{pH}_{\mathrm{PZC}}$ showed higher color strength indicating the formation of ionic bonds between dye and fiber. The dyed samples at $\mathrm{pH}$ greater than $\mathrm{pH}_{\mathrm{PZC}}$, on the contrary, resulted in lower color strength. These results demonstrate the importance of knowing the point of zero charge of protein fibers and thus determine the best dyeing $\mathrm{pH}$ of the same.

Keywords: Point of zero charge. Silk. Wool. Dyeing.

\section{INTRODUÇÃO}

A seda e a lã são consideradas fibras naturais, pois são produzidas pela natureza de forma que as tornem aptas para o processamento têxtil. São ainda classificadas como fibras de origem animal, sendo a seda produzida por secreção glandular da larva do bicho-da-seda (Bombyx mori) e a lã oriunda da atividade dos folículos pilosos presentes na pele dos ovinos comumente chamados de carneiros, ovelhas ou carneiros [1]. Tanto os filamentos da seda como os pelos dos animais são compostos basicamente de proteínas, dessa forma, estas fibras são também designadas como fibras proteicas [2, 3].

As proteínas são formadas pela polimerização de uma mistura de aminoácidos (com a fórmula geral $\left.\mathrm{NH}_{2} \cdot \mathrm{CHR} \cdot \mathrm{COOH}\right)$ por meio de ligações peptídicas $(-\mathrm{CO}-\mathrm{NH}-)$, resultando em moléculas de cadeia longa de resíduos de aminoácidos, com seus respectivos grupos laterais $\left(\mathrm{R}_{1}, \mathrm{R}_{2}\right.$ etc.). Essas moléculas são também chamadas de cadeias polipeptídicas e sua estrutura geral é apresentada na Figura 1 [4].

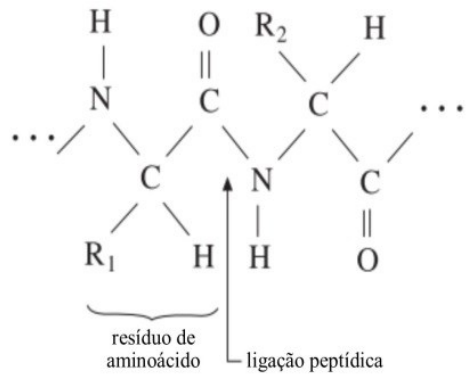

Figura 1: Estrutura química geral da proteína (adaptado de MORTON e HEARLE [4]]).

O bicho-da-seda segrega dois filamentos por meio de glândulas situadas nas laterais de sua cabeça, os quais são compostos basicamente por uma proteína chamada fibroína. Antes de deixarem o corpo da larva, estes dois filamentos são unidos por uma substância gomosa constituída pela proteína sericina [1,3]. A fibroína representa de $62,5 \%$ a $67 \%$ da fibra e a sericina de 22 a $25 \%$, sendo o restante água (10 a $11 \%$ ) e sais ( 1 a 1,5\%) [5]. A sericina também chamada de cola da seda é amorfa e solúvel em água fervente em soluções de sabão ou álcalis, sendo removida no processo de desengomagem que precede o tingimento [6,7]. Já a lã é constituída principalmente de uma proteína denominada queratina [8].

A sericina e a queratina se distinguem devido à diferente sequência e proporção dos resíduos de aminoácidos presentes nas cadeias polipeptídicas [4]. A Tabela 1 apresenta a proporção entre os grupos laterais dos aminoácidos que constituem a sericina e a queratina.

A presença dos grupos terminais e laterais do tipo ácido como a carboxila $(\mathrm{COOH})$ e do tipo básico como a amina $\left(\mathrm{NH}_{2}\right)$ nas cadeias polipeptídicas das fibras proteicas dão a elas um caráter anfotérico. Deste modo, estas fibras podem ficar carregadas negativamente ou positivamente conforme o $\mathrm{pH}$ do meio em que se encontram, sendo suscetíveis à reação com produtos catiônicos ou aniônicos [2, 9].

Devido a esta característica anfotérica, torna-se importante determinar as características eletroquímicas das fibras proteicas, pois elas influenciam nas propriedades de adsorção de corantes, surfactantes e aditivos na fibra. Esta caracterização é feita usualmente determinando o $\mathrm{pH}$ do ponto isoelétrico $\left(\mathrm{pH}_{\mathrm{PIE}}\right)$ ou o $\mathrm{pH}$ do ponto de carga zero $\left(\mathrm{pH}_{\mathrm{PCZ}}\right)$ das fibras [9-11].

$\mathrm{O}_{\mathrm{pH}} \mathrm{PIE}_{\mathrm{e}} \mathrm{e}$ o $\mathrm{pH}_{\mathrm{PCZ}}$ correspondem ao $\mathrm{pH}$ da solução aquosa, na qual substâncias anfotéricas possuem carga neutra, ou seja, tem o mesmo número de grupos amina catiônicos e carboxila aniônicos $[9,12]$. A determinação dessas duas características se diferencia principalmente pela capacidade de determinação das cargas das superfícies. Enquanto, o $\mathrm{pH}_{\mathrm{PIE}}$ determina a carga da superfície externa das partículas do adsorvente em solução, o pH $\mathrm{PCZ}_{\mathrm{PC}}$ resulta no valor total, ou seja, a carga tanto da superfície interna quanto da externa [13]. 
Segundo ROUETTE et al. [12], para anfóteros macromoleculares o ponto isoelétrico e o ponto de carga zero não coincidem necessariamente. No caso das proteínas, por exemplo, o ponto isoelétrico é influenciado pelo número de grupos ácidos e básicos livres bem como a sua posição na molécula.

Tabela 1: Proporção dos grupos laterais dos aminoácidos presentes na fibroína e na queratina.

\begin{tabular}{|c|c|c|c|c|c|c|c|c|}
\hline \multirow{3}{*}{ 을 } & \multirow{3}{*}{ GRUPO LATERAL (R) } & \multirow{3}{*}{ AMINOÁCIDO } & \multicolumn{6}{|c|}{ PROPORÇÃO (mol \%) } \\
\hline & & & \multicolumn{3}{|c|}{ FIBROIINA } & \multicolumn{3}{|c|}{ QUERATINA } \\
\hline & & & [9] & {$[14]$} & {$[15]$} & [9] & {$[14]$} & [15] \\
\hline$\stackrel{\Xi}{\Xi}$ & $\begin{array}{l}-\mathrm{H} \\
-\mathrm{CH} \\
-\mathrm{CH}\left(\mathrm{CH}_{3}\right)_{2} \\
-\mathrm{CH}_{2} \mathrm{CH}\left(\mathrm{CH}_{3}\right)_{2} \\
-\mathrm{CH}_{2}\left(\mathrm{CH}_{3}\right) \mathrm{CH}_{2} \mathrm{CH}_{3} \\
-\mathrm{CH}_{2} \mathrm{C}_{6} \mathrm{H}_{5} \\
\end{array}$ & \begin{tabular}{|l} 
Glicina \\
Alanina \\
Valina \\
Leucina \\
Isoleucina \\
Fenilalanina \\
\end{tabular} & $\begin{array}{l}42,8 \\
30,0 \\
2,5 \\
0,6 \\
0,6 \\
0,7 \\
\end{array}$ & $\begin{array}{l}44,6 \\
29,6 \\
2,2 \\
0,5 \\
0,7 \\
0,6 \\
\end{array}$ & $\begin{array}{l}43,7 \\
28,8 \\
2,2 \\
0,5 \\
0,7 \\
0,6 \\
\end{array}$ & $\begin{array}{l}8,2 \\
5,4 \\
5,7 \\
7,7 \\
3,1 \\
2,8 \\
\end{array}$ & $\begin{array}{l}8,4 \\
5,4 \\
5,6 \\
7,7 \\
3,1 \\
2,9 \\
\end{array}$ & $\begin{array}{l}8,4 \\
5,5 \\
5,6 \\
7,8 \\
3,3 \\
2,8 \\
\end{array}$ \\
\hline$\frac{0}{\frac{0}{0}}$ & $\begin{array}{l}-\mathrm{CH}_{2} \mathrm{COOH} \\
-\mathrm{CH}_{2} \mathrm{CH}_{2} \mathrm{COOH}\end{array}$ & $\begin{array}{l}\text { Ácido aspártico } \\
\text { Ácido glutâmico }\end{array}$ & $\begin{array}{l}1,9 \\
1,4\end{array}$ & $\begin{array}{l}1,3 \\
1,0\end{array}$ & $\begin{array}{l}1,3 \\
1,0\end{array}$ & $\begin{array}{l}6,6 \\
11,9\end{array}$ & $\begin{array}{l}6,5 \\
11,9\end{array}$ & $\begin{array}{l}5,6 \\
11,3\end{array}$ \\
\hline 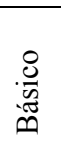 & $\begin{array}{c}-\mathrm{CH}_{2} \mathrm{CH}_{2} \mathrm{CH}_{2} \mathrm{CH}_{2} \mathrm{NH}_{2} \\
-\left(\mathrm{CH}_{2}\right)_{3} \mathrm{NHC}(\mathrm{NH}) \mathrm{NH}_{2} \\
\stackrel{\mathrm{N}: \mathrm{CH}}{-\mathrm{CH}_{2}}\end{array}$ & $\begin{array}{l}\text { Lisina } \\
\text { Arginina } \\
\text { Histidina }\end{array}$ & $\begin{array}{l}0,4 \\
0,5 \\
0,2\end{array}$ & $\begin{array}{l}0,3 \\
0,5 \\
0,1\end{array}$ & $\begin{array}{l}0,3 \\
0,5 \\
0,2\end{array}$ & $\begin{array}{l}2,8 \\
6,9 \\
0,8\end{array}$ & $\begin{array}{l}2,9 \\
6,9 \\
0,9\end{array}$ & $\begin{array}{l}2,6 \\
6,4 \\
0,9\end{array}$ \\
\hline 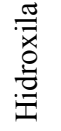 & $\begin{array}{l}-\mathrm{CH}_{2} \mathrm{OH} \\
-\mathrm{CH}(\mathrm{OH}) \mathrm{CH}_{3} \\
-\mathrm{CH}_{2} \mathrm{C}_{6} \mathrm{H}_{4} \mathrm{OH}\end{array}$ & $\begin{array}{l}\text { Serina } \\
\text { Treonina } \\
\text { Tirosina }\end{array}$ & $\begin{array}{l}12,2 \\
0,9 \\
4,8\end{array}$ & $\begin{array}{l}12,1 \\
0,9 \\
5,2\end{array}$ & $\begin{array}{l}11,9 \\
0,9 \\
5,1\end{array}$ & $\begin{array}{l}10,5 \\
6,3 \\
4,0\end{array}$ & $\begin{array}{l}10,4 \\
6,4 \\
3,8\end{array}$ & $\begin{array}{l}11,6 \\
6,9 \\
3,5\end{array}$ \\
\hline$\frac{\stackrel{*}{*}}{\frac{\pi}{ \pm}}$ & $\begin{array}{l}-\mathrm{CH}_{2} \backslash \mathrm{CH}_{2} \\
-\mathrm{CH}_{2} /\end{array}$ & Prolina & 0,5 & 0,4 & 0,5 & 7,2 & 6,6 & 6,8 \\
\hline 苂 & $-\mathrm{CH}_{2} \mathrm{SSCH}_{2}-$ & Cistina & 0,1 & 0,2 & 0,2 & 10,0 & 10,3 & 9,8 \\
\hline $\begin{array}{l}0 \\
\frac{6}{0} \\
\stackrel{D}{0} \\
0\end{array}$ & $-\mathrm{CH}_{2} \mathrm{CH}_{2} \mathrm{SCH}_{3}$ & $\begin{array}{l}\text { Metionina } \\
\text { Triptofano }\end{array}$ & $\begin{array}{l}0 \\
-\end{array}$ & $\begin{array}{l}0,1 \\
0,1\end{array}$ & $\overline{-}-3$ & $\begin{array}{l}0,4 \\
-\end{array}$ & $\begin{array}{l}0,5 \\
0,5\end{array}$ & $\begin{array}{l}0,4 \\
0,5\end{array}$ \\
\hline$*$ En & a-se na cadeia molecular & & & ncontr: & tre dua & adeias $\mathrm{p}$ & peptídica & omo: \\
\hline
\end{tabular}

As fibras proteicas devem ser tingidas de preferência em meio ácido, pois são degradadas em meio alcalino. Além disso, melhores resultados para o tingimento dessas fibras são obtidos em condições ácidas, pois tais fibras apresentam $\mathrm{pH}_{\mathrm{PIE}}$ na região ácida. Essas fibras podem ser tingidas com corantes do tipo ácido, ao mordente e reativo. Porém, a classe mais utilizada é a de corantes ácidos $[6,16,17]$.

Os corantes ácidos são assim chamados por serem aplicados em meio ácido. Normalmente os corantes ácidos apresentam-se na forma de sais de sódio de ácidos sulfônicos ou, com menor frequência, de ácidos carboxílicos e são, portanto, aniônicos em solução aquosa, conforme mostra o esquema da Figura 2 [18].

$$
\text { Corante- } \mathrm{SO}_{3}{ }^{-} \mathrm{Na}^{+} \stackrel{\mathrm{H}_{2} \mathrm{O}}{\longrightarrow} \text { Corante }-\mathrm{SO}_{3}^{-}+\mathrm{Na}^{+}
$$

Figura 2: Esquema de ionização de corantes ácidos em solução aquosa. 
No ponto isoelétrico, os grupos amina e carboxila das fibras proteicas são ionizados transformando-se em $\mathrm{NH}_{3}{ }^{+}$e $\mathrm{COO}^{-}$, respectivamente. À medida que o $\mathrm{pH}$ ultrapassa este ponto, a fibra torna-se carregada negativamente, como resultado da desprotonação dos grupos amina devido à adição de uma base. Já em um banho de tingimento ácido, conforme esquematizado na Figura 3, ocorre o inverso: à medida que o pH atinge valores inferiores ao ponto isoelétrico, os ânions carboxilatos são progressivamente neutralizados pela adsorção de prótons devido à adição de um ácido (ex. $\mathrm{HCl})$, o que provoca a carga positiva na fibra que atrai uma quantidade equivalente de ânions $\mathrm{Cl}^{-}$do ácido $[19,20]$.

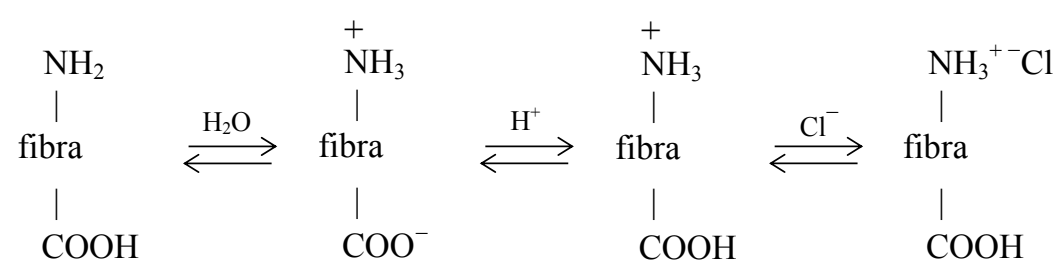

Figura 3: Esquema de ionização da fibra proteica na presença de um ácido.

$\mathrm{O}$ processo de tingimento consiste numa substituição dos ânions do ácido absorvidos $\left(\mathrm{Cl}^{-}\right)$pelos ânions de corante adicionados (Corante- $\mathrm{SO}_{3}{ }^{2}$ ), conforme mostra o esquema da Figura 4, desde que os ânions do corante possuam uma maior afinidade para o substrato do que ânions de ácido. Assim, o corante está ligado à fibra, não só por atração eletrostática, mas também pela sua afinidade para a fibra [19].

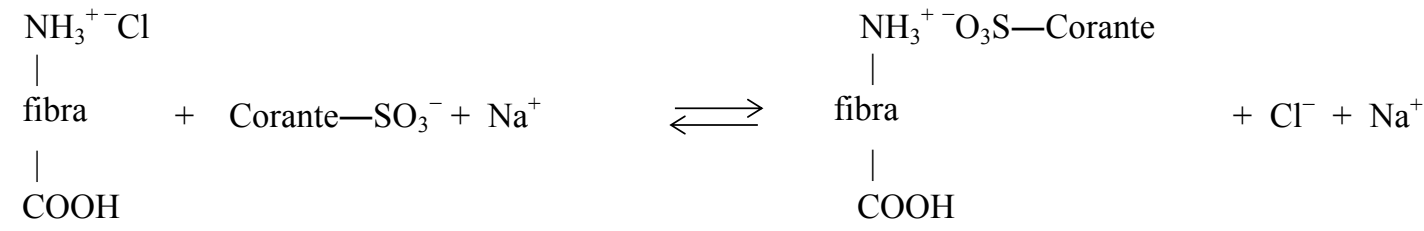

Figura 4: Esquema de troca iônica no tingimento ácido de fibras proteicas.

$\mathrm{O} \mathrm{pH}_{\mathrm{PIE}}$ de fibras têxteis pode ser determinado por métodos eletrocinéticos que incluem eletroforese, potencial de sedimentação, eletro-osmose e potencial de corrente [9, 11]. Já com relação ao $\mathrm{pH}_{\mathrm{PCZ}}$, não existem relatos na literatura sobre sua determinação para as fibras de seda e lã. Dessa forma, o presente trabalho determinou o $\mathrm{pH}_{\mathrm{PCZ}}$ de tecidos de seda e lã prontos para tingir por meio do método "experimento dos 11 pontos" que necessita de um aparato experimental simples e acessível.

\section{MATERIAIS E MÉTODOS}

\subsection{Determinação do ponto de carga zero das fibras}

Amostras de tecido de seda e de lã prontos para tingir foram reduzidos à fibra triturada por meio de picotamento com tesoura. Estas fibras trituradas foram utilizadas no experimento para a determinação do ponto de carga zero das mesmas. A metodologia empregada foi baseada no método do "experimento dos 11 pontos" proposto por REGALBUTO e ROBLES [21].

Soluções de cloreto de sódio $0,1 \mathrm{~mol} \mathrm{~L}^{-1}$ sob 11 diferentes valores de $\mathrm{pH}$ inicial $(2,3,4,5,6,7,8,9$, $10,11,12)$ foram preparadas usando água deionizada e o pH de cada solução foi ajustado, conforme necessário, com soluções de ácido clorídrico ou hidróxido de sódio $0,1 \mathrm{~mol} \mathrm{~L}^{-1}$. Após o ajuste de $\mathrm{pH}$ das soluções, foram adicionados $20 \mathrm{~mL}$ de cada solução em tubos de ensaio com tampa rosqueável e, em seguida, acrescentados $20 \mathrm{mg}$ de fibra triturada em cada tubo. Os tubos foram tampados e mantidos sob agitação em um banho maria tipo Dubnoff com movimento orbital a uma temperatura controlada de $25{ }^{\circ} \mathrm{C}$ durante 24 horas. Após este período, as soluções foram filtradas em papel filtro qualitativo e os valores do $\mathrm{pH}$ final determinados com auxílio de pHmetro de bancada. Todo o procedimento foi realizado em triplicata.

Para cada fibra analisa foi construído um gráfico do $\mathrm{pH}$ final versus $\mathrm{pH}$ inicial. O ponto de carga zero de cada fibra foi obtido ao calcular a média entre os pontos do $\mathrm{pH}$ final que tendem a um mesmo valor.

\subsection{Efeito do ponto de carga zero no tingimento das fibras}

Para avaliar o efeito do $\mathrm{pH}_{\mathrm{PCZ}}$ no tingimento das fibras de seda e lã analisadas, realizou-se o tingimento de ambas as fibras com um corante ácido. Para ambos os tipos de fibras, foram utilizadas duas amostras de teci- 
do pronto para tingir, em uma dessas amostras o tingimento foi realizado com valor de $\mathrm{pH} \quad 0,5$ unidade menor do que o $\mathrm{pH}_{\mathrm{PCZ}}$ e a outra amostra foi tingida com valor de $\mathrm{pH} \quad 0,5$ unidade maior do que o $\mathrm{pH}_{\mathrm{PCZ}}$.

As amostras foram tintas por processo de esgotamento no equipamento de tingimento em canecas $\mathrm{Ki}$ mak AT1-SW utilizando 2\% spm. de corante ácido Nylosan Azul EBGL 200 (C.I. Acid Blue 324) com uma relação de banho $1: 100$ na temperatura de $80{ }^{\circ} \mathrm{C}$ durante 40 minutos. $\mathrm{O} \mathrm{pH}$ das soluções de tingimento foi ajustado com ácido acético e carbonato de sódio, conforme a necessidade. Após o tingimento, as amostras foram enxaguadas em agua corrente e secas à temperatura ambiente.

A intensidade da coloração das amostras obtida após o tingimento foi avaliada por meio dos valores de K/S calculados pela equação de Kubelka-Munk (Equação 1):

$$
\frac{K}{S}=\frac{(1-R)^{2}}{2 R}
$$

em que $K / S$ é a intensidade colorística, $R$ é a fração da refletância que foi obtida pelo espectrofotômetro de refletância DataColor $550, K$ o coeficiente de absorção e S é o coeficiente de difusão [1, 12].

\section{RESULTADOS E DISCUSSÃO}

\subsection{Determinação do ponto de carga zero das fibras}

As Tabelas 2 e 3 apresentam os valores de $\mathrm{pH}$ inicial, $\mathrm{pH}$ final, média dos valores de $\mathrm{pH}$ final juntamente com o desvio-padrão obtidos nos ensaios utilizando a fibra de seda e de lã, respectivamente.

Tabela 2: Valores de $\mathrm{pH}$ inicial, $\mathrm{pH}$ final, média e desvio-padrão dos $\mathrm{pH}$ finais para os ensaios com a fibra de seda.

\begin{tabular}{|c|c|c|c|c|}
\hline ENSAIO & PH INICIAL & PH FINAL & MÉDIA DO PH FINAL & DESVIO-PADRÃO \\
\hline 1 & \multirow{3}{*}{1,998} & 3,177 & \multirow{3}{*}{2,423} & \multirow{3}{*}{0,533} \\
\hline 2 & & 2,048 & & \\
\hline 3 & & 2,043 & & \\
\hline 4 & \multirow{3}{*}{3,009} & 3,542 & \multirow{3}{*}{3,479} & \multirow{3}{*}{0,259} \\
\hline 5 & & 3,760 & & \\
\hline 6 & & 3,134 & & \\
\hline 7 & \multirow{3}{*}{3,993} & 3,812 & \multirow{3}{*}{3,469} & \multirow{3}{*}{0,244} \\
\hline 8 & & 3,262 & & \\
\hline 9 & & 3,332 & & \\
\hline 10 & \multirow{3}{*}{4,996} & 3,761 & \multirow{3}{*}{3,814} & \multirow{3}{*}{0,037} \\
\hline 11 & & 3,839 & & \\
\hline 12 & & 3,842 & & \\
\hline 13 & \multirow{3}{*}{6,008} & 3,834 & \multirow{3}{*}{3,832} & \multirow{3}{*}{0,008} \\
\hline 14 & & 3,841 & & \\
\hline 15 & & 3,822 & & \\
\hline 16 & \multirow{3}{*}{7,006} & 3,822 & \multirow{3}{*}{3,852} & \multirow{3}{*}{0,036} \\
\hline 17 & & 3,830 & & \\
\hline 18 & & 3,903 & & \\
\hline 19 & \multirow{3}{*}{8,008} & 3,839 & \multirow{3}{*}{3,852} & \multirow{3}{*}{0,014} \\
\hline 20 & & 3,847 & & \\
\hline 21 & & 3,871 & & \\
\hline 22 & \multirow{3}{*}{9,002} & 4,975 & \multirow{3}{*}{5,267} & \multirow{3}{*}{0,394} \\
\hline 23 & & 5,003 & & \\
\hline 24 & & 5,824 & & \\
\hline 25 & \multirow{3}{*}{10,000} & 5,596 & \multirow{3}{*}{5,974} & \multirow{3}{*}{0,418} \\
\hline 26 & & 5,769 & & \\
\hline 27 & & 6,556 & & \\
\hline 28 & \multirow{3}{*}{11,005} & 6,511 & \multirow{3}{*}{6,416} & \multirow{3}{*}{0,398} \\
\hline 29 & & 5,888 & & \\
\hline 30 & & 6,848 & & \\
\hline 31 & & 9,62 & & \\
\hline 32 & 12,010 & 9,665 & 9,401 & 0,342 \\
\hline 33 & & 8,917 & & \\
\hline
\end{tabular}


Tabela 3: Valores de pH inicial, pH final, média e desvio-padrão dos pH finais para os ensaios com a fibra de lã.

\begin{tabular}{|c|c|c|c|c|}
\hline ENSAIO & PH INICIAL & PH FINAL & MÉDIA DO PH FINAL & DESVIO-PADRÃO \\
\hline 1 & \multirow{3}{*}{1,998} & 2,616 & \multirow{3}{*}{2,614} & \multirow{3}{*}{0,029} \\
\hline 2 & & 2,648 & & \\
\hline 3 & & 2,578 & & \\
\hline 4 & \multirow{3}{*}{3,009} & 4,784 & \multirow{3}{*}{4,815} & \multirow{3}{*}{0,027} \\
\hline 5 & & 4,850 & & \\
\hline 6 & & 4,811 & & \\
\hline 7 & \multirow{3}{*}{3,993} & 6,443 & \multirow{3}{*}{6,363} & \multirow{3}{*}{0,105} \\
\hline 8 & & 6,214 & & \\
\hline 9 & & 6,431 & & \\
\hline 10 & \multirow{3}{*}{4,996} & 6,123 & \multirow{3}{*}{6,163} & \multirow{3}{*}{0,069} \\
\hline 11 & & 6,105 & & \\
\hline 12 & & 6,260 & & \\
\hline 13 & \multirow{3}{*}{6,008} & 5,868 & \multirow{3}{*}{6,071} & \multirow{3}{*}{0,145} \\
\hline 14 & & 6,153 & & \\
\hline 15 & & 6,193 & & \\
\hline 16 & \multirow{3}{*}{7,006} & 6,370 & \multirow{3}{*}{6,330} & \multirow{3}{*}{0,106} \\
\hline 17 & & 6,185 & & \\
\hline 18 & & 6,435 & & \\
\hline 19 & \multirow{3}{*}{8,008} & 6,428 & \multirow{3}{*}{6,368} & \multirow{3}{*}{0,060} \\
\hline 20 & & 6,390 & & \\
\hline 21 & & 6,286 & & \\
\hline 22 & \multirow{3}{*}{9,002} & 5,061 & \multirow{3}{*}{5,294} & \multirow{3}{*}{0,215} \\
\hline 23 & & 5,242 & & \\
\hline 24 & & 5,579 & & \\
\hline 25 & \multirow{3}{*}{10,000} & 5,887 & \multirow{3}{*}{5,473} & \multirow{3}{*}{0,293} \\
\hline 26 & & 5,273 & & \\
\hline 27 & & 5,259 & & \\
\hline 28 & \multirow{3}{*}{11,005} & 7,272 & \multirow{3}{*}{7,252} & \multirow{3}{*}{0,014} \\
\hline 29 & & 7,244 & & \\
\hline 30 & & 7,240 & & \\
\hline 31 & & 11,644 & & \\
\hline 32 & 12,010 & 11,605 & 11,653 & 0,043 \\
\hline 33 & & 11,710 & & \\
\hline
\end{tabular}

Gráficos com os valores médios do $\mathrm{pH}$ final versus os valores de $\mathrm{pH}$ inicial juntamente com os desvios-padrão dos pH finais para a fibra de seda e de lã são mostrados nas Figuras 5 e 6, respectivamente.

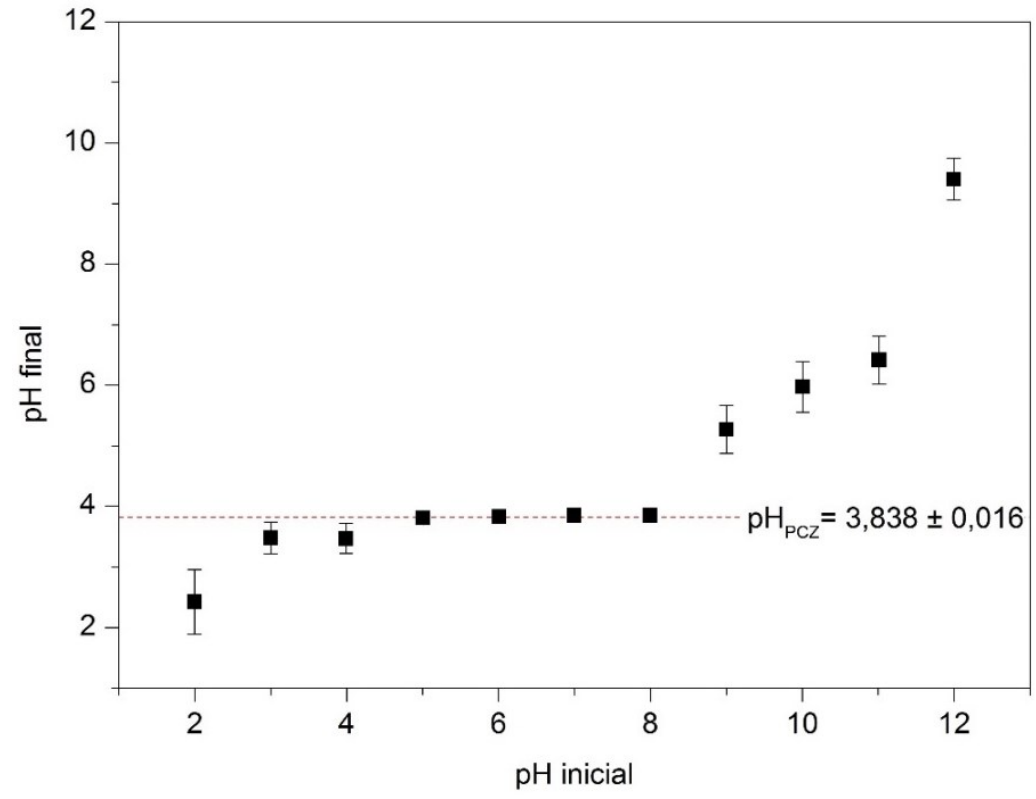

Figura 5: Valores médios de $\mathrm{pH}$ final versus $\mathrm{pH}$ inicial obtidos para a fibra de seda. 


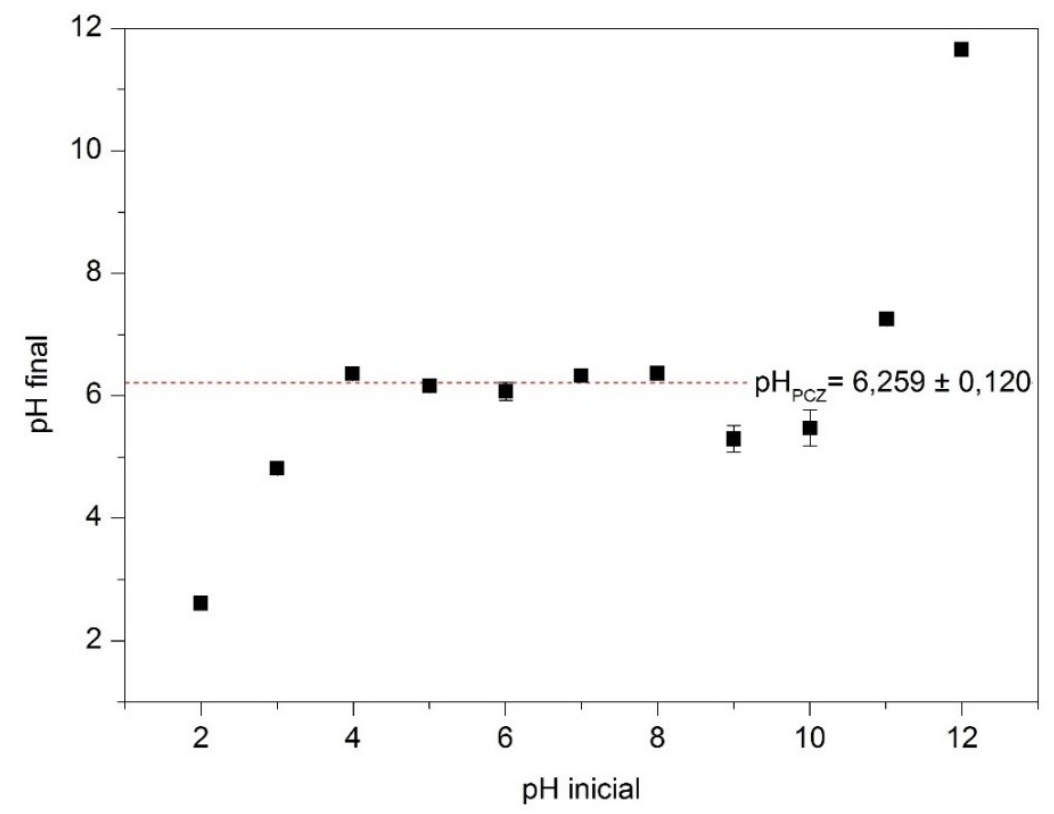

Figura 6: Valores médios de $\mathrm{pH}$ final versus $\mathrm{pH}$ inicial obtidos para a fibra de lã.

$\mathrm{O}$ valor do $\mathrm{pH}_{\mathrm{PCZ}}$ para cada fibra foi calculado fazendo-se a média aritmética dos pontos de $\mathrm{pH}$ final que se apresentaram constantes. Para a fibra de seda os ensaios efetuados com pH inicial de 5 a 8 (ensaios 10 a 21) apresentaram valores de $\mathrm{pH}$ final próximos um dos outros, com média igual a 3,838. Já para a fibra de lã, os ensaios efetuados com pH inicial de 4 a 8 (ensaios 7 a 21) apresentaram valores de $\mathrm{pH}$ final aproximados com média igual a 6,259 .

$\mathrm{O} \mathrm{pH}_{\mathrm{PCZ}}$ obtido para ambas as fibras corresponde à faixa na qual o $\mathrm{pH}$ final se mantém constante, independentemente do pH inicial, ou seja, quando a fibra se comporta como um tampão [22].

De acordo com ROUETTE et al. [12] o $\mathrm{pH}_{\mathrm{PIE}}$ depende da proporção entre grupos carboxila e amino ionizados, dessa forma, um $\mathrm{pH}_{\mathrm{PCZ}}$ na região ácida já era o esperado para ambas as fibras proteicas. Isso se deve ao fato de que as duas proteínas apresentam uma maior proporção de grupos laterais ácidos em relação aos grupos laterais básicos. Conforme pode ser verificado na Tabela 1, o total de grupos laterais ácidos na fibroína e na queratina é, em média, cerca de duas vezes maior que o dos grupos laterais básicos.

Porém a carga que um material de proteína, tal como a seda e a lã, apresenta a um dado valor de $\mathrm{pH}$ não depende só do número de grupos laterais que possuem grupos $-\mathrm{NH}_{2} \mathrm{e}-\mathrm{COOH}$, mas também dos valores de $\mathrm{pK}_{\mathrm{a}}$ desses grupos. $\mathrm{O}$ valor do $\mathrm{pK}_{\mathrm{a}}$ representa o grau de ionização, quanto menor o $\mathrm{pK}_{\mathrm{a}}$ da função química, mais esta se dissocia em solução aquosa, tornando a solução mais ácida, ou seja, liberando mais prótons na forma de $\mathrm{H}^{+}$.

Segundo PACE et al. [23] o grupo funcional - $\mathrm{COOH}$ dos aminoácidos ácido aspártico e ácido glutâmico apresenta um valor de $\mathrm{pK}_{\mathrm{a}}$ igual a 3,9 e 4,3, respectivamente. Já o grupo funcional $-\mathrm{NH}_{2}$ dos aminoácidos lisina, arginina e histidina presenta $\mathrm{pK}_{\mathrm{a}}$ igual a 10,4, 12,3 e 6,5, respectivamente.

A um pH baixo, os grupos ionizáveis de ácido aspártico e do ácido glutâmico estão na forma não ionizada $(-\mathrm{COOH})$, mas os grupos da lisina e arginina e a histidina estão na forma protonada $\left(-\mathrm{NH}_{3}{ }^{+}\right)$. Com o aumento do $\mathrm{pH}$, a proteína começa a perder prótons, devido à ionização dos grupos carboxila e estes grupos aniônicos decorrentes reduzem a carga positiva líquida da proteína. A pH 3,9 (o pK $\mathrm{a}_{\mathrm{a}}$ dos grupos $-\mathrm{COOH}$ nos resíduos de ácido aspártico), os grupos carboxila estão 50\% ionizados. Com a continuação do aumento do $\mathrm{pH}$, mais prótons são perdidos, até que no $\mathrm{pH} 6,5$ (o o $\mathrm{pK}_{\mathrm{a}}$ dos grupos $-\mathrm{NH}_{2}$ nos resíduos da histidina) metade dos grupos $-\mathrm{NH}_{3}{ }^{+}$da histidina perdem prótons.

Dessa forma, na faixa de $\mathrm{pH}$ 3,9 a 6,5, o número de grupos positivos e negativos tendem a serem iguais. Assim, a proteína irá transportar uma carga líquida igual a zero, sendo esta a faixa do $\mathrm{pH}_{\mathrm{PCZ}}$ da sericina e da queratina.

Aumentando ainda mais o $\mathrm{pH}$ do meio, mais prótons são perdidos, sendo que no $\mathrm{pH} 10,4$ (o o $\mathrm{pK}_{\mathrm{a}}$ dos grupos $-\mathrm{NH}_{2}$ nos resíduos da lisina) metade dos grupos $-\mathrm{NH}_{3}{ }^{+}$perdem prótons. Os resíduos de arginina mais básicos (grupos $-\mathrm{NH}_{2}$ com $\mathrm{pK}_{\mathrm{a}}=12,3$ ) começam a perder prótons a valores de $\mathrm{pH}$ mais elevados.

Não foram encontrados na literatura estudos referentes à determinação do $\mathrm{pH}_{\mathrm{PCZ}}$ para fibra de seda $\mathrm{e}$ lã. No entanto, os valores do $\mathrm{pH}_{\mathrm{PCZ}}$ obtidos podem ser correlacionados com os valores de $\mathrm{pH}_{\mathrm{PIE}}$, uma vez que 
a definição dessas duas características é parecida. Para a seda, o valor do $\mathrm{pH}_{\mathrm{PCZ}}$ igual a 3,8 correspondeu exatamente ao $\mathrm{pH}_{\mathrm{PIE}}$ da fibroína determinado por KAN [24] utilizando a técnica de determinação do potencial zeta. Ainda de acordo com AYUB et al. [25] e AYUB et al. [26] o $\mathrm{pH}_{\mathrm{PIE}}$ da fibroína situa-se entre 3,8-3,9. Já para a fibra de lã, o valor do $\mathrm{pH}_{\mathrm{PCZ}}$ igual a 6,3 ficou dentro da faixa do $\mathrm{pH}_{\mathrm{PIE}}$ da lã indicado TROTMAN

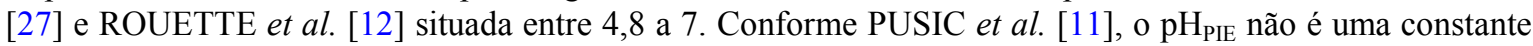
física, uma vez que depende do grau de impurezas, aditivos, preparações e acabamentos na aplicados na fibra, isto explica a variação nos valores do $\mathrm{pH}$ PIE.

\subsection{Efeito do ponto de carga zero no tingimento das fibras}

Os valores da intensidade colorística (K/S) e coloração obtidos nos tingimentos das amostra de tecido de seda e lã com pH acima e abaixo do $\mathrm{pH}_{\mathrm{PCZ}}$ são apresentados na Tabela 4.

Tabela 4: Intensidade colorística e coloração obtidos nos tingimentos de seda e lã em pH acima e abaixo do $\mathrm{pH}_{\mathrm{PCZ}}$.

\begin{tabular}{l|l|l|l|l}
\hline FIBRA & PH $_{\mathrm{PCZ}}$ & PH DE TINGIMENTO & $\begin{array}{l}\text { INTENSIDADE } \\
\text { COLORÍSTICA (K/S) }\end{array}$ & COLORAÇÃO \\
\hline \multirow{2}{*}{ Seda } & \multirow{2}{*}{3,838} & 3,3 & 8,29 & \\
\cline { 3 - 5 } & \multirow{2}{*}{ Lã } & 4,3 & 2,05 & \\
& \multirow{2}{*}{6,259} & 5,8 & 10,79 & \\
\cline { 3 - 5 } & & 6,8 & 8,68 & \\
\hline
\end{tabular}

No pH menor que o ponto de carga zero, o nitrogênio dos grupos amina $\left(\mathrm{NH}_{2}\right)$ situados nas cadeias polipeptídicas das fibras adsorvem íons de hidrogênio criando sítios de carga positiva. Estes sítios têm uma forte atração para corantes aniônicos como os corantes ácidos, fazendo com que a adsorção do corante aumente consideravelmente. Como no tingimento a intensidade colorística $(\mathrm{K} / \mathrm{S})$ está diretamente relacionada à quantidade de corante absorvida pelo tecido, os tingimentos realizados em $\mathrm{pH}$ menor que o $\mathrm{pH}_{\mathrm{PCZ}}$ apresentaram maiores valores de $\mathrm{K} / \mathrm{S}$ do que os tingimentos realizados em $\mathrm{pH}$ maiores que o $\mathrm{pH}_{\mathrm{PCZ}}$.

Já no pH maior que o ponto de carga zero, a fibra apresenta sítios carregados negativamente, como resultado da desprotonação dos grupos amina devido à adição de uma base. Estes sítios negativos repelem as moléculas aniônicas do corante ácido, causando uma menor adsorção do mesmo e consequentemente menores valores de intensidade colorística. Porém, além destas forças da atração iônicas, forças de Van der Waals e de ligação hidrogênio entre a funcionalidade adequada das moléculas de corante e da fibra, também podem desempenhar um papel no tingimento ácido de fibras proteicas [12, 16, 19]. Este fato explica o tingimento das fibras em $\mathrm{pH}$ maior que o $\mathrm{pH}_{\mathrm{PCZ}}$.

\section{CONCLUSÕES}

O conhecimento do $\mathrm{pH}$ do ponto de carga zero das fibras de seda e lã revelou-se de grande importância para a realização de processos a úmido, como o tingimento. A partir do seu valor foi possível conhecer o tipo de carga iônica que as fibras continham quando imersas no banho de tingimento. A determinação desta característica eletrocinética a partir do método "experimento dos 11 pontos" mostrou-se simples e acessível, pois necessita de equipamentos comuns de laboratório, como pHmetro de bancada e banho maria tipo Dubnoff.

Para a fibra de seda e lã, foram encontrados $\mathrm{pH}$ do ponto de carga zero na região ácida correspondentes a 3,8 e 6,3 respectivamente. Estes valores na região ácida devem-se ao fato de a sericina da seda e a queratina da lã apresentarem uma maior proporção de grupos laterais ácidos em relação aos grupos laterais básicos. Além disso, os grupos ácidos por possuírem valores de $\mathrm{pK}_{\mathrm{a}}$ menores do que os grupos básicos, tornamse dissociados em soluções aquosa, liberando mais $\mathrm{H}^{+}$de forma a tornar o meio líquido mais ácido.

As amostras de seda e de lã tingidas em $\mathrm{pH}$ menor que o $\mathrm{pH}_{\mathrm{PCZ}}$, apresentaram maior intensidade colorística, evidenciando a maior adsorção do corante ácido devido à formação de ligações iônicas entre corante e a fibra. Já as amostras tingida em $\mathrm{pH}$ maior que $\mathrm{o} \mathrm{pH}_{\mathrm{PCZ}}$, pelo contrário, resultaram em menor intensidade colorística, ou seja, menos adsorção do corante. Estes resultados comprovam a importância de se conhecer o ponto de carga zero das fibras proteicas e assim, determinar o melhor $\mathrm{pH}$ de tingimento das mesmas.

\section{AGRADECIMENTOS}

Ao Instituto Vale da Seda e ao Grupo Paramount Têxteis. O presente foi realizado com o apoio da Coordenação de Aperfeiçoamento de Pessoal de Nível Superior - CAPES - Brasil. 


\section{BIBLIOGRAFIA}

[1] ARAÚJO, M., CASTRO, E.M.M., Manual de engenharia têxtil, Lisboa, Calouste Gulbenkian, 1986.

[2] SALEM, V., Tingimento têxtil: fibras, conceitos e tecnologias, São Paulo, Blucher, 2010.

[3] NEEDLES, H.L., Textile fibers, dyes, finishes, and processes: a concise guide, New Jersey, Noyes Publications, 1986.

[4] MORTON, W.E., HEARLE, J.W.S., Physical properties of textile fibres, 4 ed., Cambridge, Woodhead Publishing, 2008.

[5] LEWIN, M., Handbook of fiber chemistry, 3 ed., Boca Raton, CRC Press, 2006.

[6] IQBAL, M., Textile dyes, Karachi, Rahber Publishers, 2008.

[7] KARMAKAR, S.R., Chemical technology in the pre-treatment processes of textiles, Amsterdam, Elsevier, 1999.

[8] RIPPON, J.A. "The structure of wool". In: Lewis, D.M., Rippon, J.A. (eds), The coloration of wool and other keratin fibres, chapter 1, Oxford, John Wiley \& Sons, 2013.

[9] BURKINSHAW, S.M., Physico-chemical aspects of textile coloration, West Yorkshire, John Wiley \& Sons. 2016.

[10] GRANCARIC, A.M., TARBUK, A., PUSIC, T. "Electrokinetic properties of textile fabrics", Coloration Technology, v. 121, pp. 221-227, May. 2005.

[11] PUSIC, T., GRANCARIC, A.M., SOLJACIC, I., et al., "The effect of mercerisation on the electrokinetic potential of cotton”, The Society of Dyers and Colourists, v. 115, pp. 121-124, Apr. 1999.

[12] ROUETTE, H.K., LINDNER, A., SCHWAGER, B., Encyclopedia of textile finishing, Aachen, Springer, 2001.

[13] MENÉNDEZ, J., ILLÁN-GÓMEZ, M., RADOVIC, L. “On the difference between the isoelectric point and the point of zero charge of carbons", Carbon, v. 33, n. 11, pp. 1655-1657, 1995.

[14] MATHER, R.R., WARDMAN, R.H., The chemistry of textile fibres, 2 ed., Cambridge, The Royal Society of Chemistry, 2015.

[15] BABU, K.M., Silk: processing, properties and applications, Oxford, Woodhead Publishing, 2013.

[16] CHRISTIE, R.M., Colour chemistry, Cambridge, Royal Society of Chemistry, 2001.

[17] KHAN, M.A., Dyeing of wool and silk fibres with a conductive polyelectrolyte and comparing their conductance, Dissertação de M.Sc., University of Båras, Borås, 2011.

[18] UDDIN, K., HOSSAIN, S. “A comparitive study on silk dyeing with acid dye and reactive dye", International Journal of Engineering \& Technology, v. 10, n. 6, pp. 1-6, Dec. 2010.

[19] HUNGER, K., Industrial dyes: chemistry, properties, applications, Weinheim, Wiley-Verlag, 2002.

[20] SHORE, J., Colorants and auxiliaries: colorants, 2 ed., Hampshire, Society of Dyers and Colourists, 2002.

[21] RegalButO, J.R., ROBLES, J. The engineering of Pt/Carbon Catalyst Preparation, University of Illinois, Chicago, 2004.

[22] GUILARDUCI, V.V.S., MESQUITA, J.P., MARTELLI, P.B., et al., “Adsorção de fenol sobre carvão ativado em meio alcalino", Química Nova, v. 29, n. 6, pp. 1226-1232, 2006.

[23] PACE, C.N., GRIMSLEY, G.R., SCHOLTZ, J.M., "Protein ionizable groups: pK values and their contribution to protein stability and solubility", Journal of Biological Chemistry, v. 284, n. 20, pp. 13285 13289, May. 2009.

[24] KAN, C., "Electrokinetic study of water hardness during acid dyeing with silk", Fibres \& textiles in Eastern Europe. v.16, n. 3, pp. 99-101, Jul. 2008.

[25] AYUB, H., ARAI, M., HIRABAYASHI, K., "Mechanism of the gelation of fibroin solution", Bioscience, biotechnology, and biochemistry, v. 57, n.11, pp. 1910-1912, 1993.

[26] AYUB, Z.H., KUME, Y., “Gleation of silk fibroin”, Trasaction, v. 46, n. 11, pp. 93-96, 1990.

[27] TROTMAN, E.R., Dyeing and chemical technology of textile fibres, 4 ed., London, Charles Griffin, 1970 . 